\title{
Development of a Food Frequency and Quantity Method for Assessing Dietary Habits of Japanese Individuals - Comparison with Results from 24hr Recall Dietary Survey
}

\author{
Nagako Chiba ${ }^{1}$, Nagako Okuda², Akira Okayama ${ }^{3}$, Takashi Kadowaki², and Hirotsugu Ueshima ${ }^{2}$ \\ ${ }^{1}$ Department of Health and Nutrition, Tsukuba International Junior College, Tsuchiura, Japan \\ ${ }^{2}$ Department of Health Science, Shiga University of Medical Sciences, Otsu, Japan \\ ${ }^{3}$ The First Institute for Health Promotion and Health Care, Japan Anti-Tuberculosis Assoc., Tokyo, Japan
}

\begin{abstract}
Aim: In a lifestyle modification program for the prevention of cardiovascular disease, quantitative assessment of the diet is essential. We developed a new food frequency and quantity method using portion-sized food models to apply in a lifestyle modification program.

Methods: We conducted a dietary survey using this method of Japanese middle-aged men and women $(n=76)$ who had undergone four $24 \mathrm{hr}$ dietary recalls one year before, and compared the results from the two surveys.

Results: Total energy intake and gram intake of macronutrients determined by our method were significantly lower than those determined by $24 \mathrm{hr}$ recalls. Correlation coefficients between nutrient intake obtained by the two methods were significant: $r=0.532(p<0.001)$ for carbohydrate, $r=0.327$ $(p=0.004)$ for protein, $r=0.334(p=0.003)$ for total fat, $r=0.419(p<0.001)$ for saturated fatty acid, and $r=0.230(p=0.046)$ for polyunsaturated fatty acid. Correlations of nutrient intake were significantly increased with energy adjustment $(p<0.05)$. Correlation coefficients between major food group intake were also significant: $r=0.682(p<0.001)$ for cereals, $r=0.261(p=0.023)$ for meat, and $r=0.333(p=0.003)$ for fish and shellfish.

Conclusion: This method was thought to be appropriate for quantitative assessment of the intake of major nutrients and food groups of individuals in Japan.
\end{abstract}

J Atheroscler Thromb, 2008; 15:324-333.

Key words; Lifestyle modification, Cardiovascular disease, Epidemiology, Dietary survey

\section{Introduction}

For prevention of cardiovascular disease (CVD), it is essential to control dietary habits ${ }^{1}$. Several dietary factors are known to relate to CVD risk factors ${ }^{2)}$ : higher saturated fatty acid (SFA) intake to higher serum low density lipoprotein (LDL) cholesterol level, lower fish intake to lower serum high density lipoprotein (HDL) cholesterol ${ }^{3)}$ and higher triglyceride level ${ }^{4)}$. Clinical trials have shown the beneficial effects of life-

Address for correspondence: Nagako Chiba, Department of Health and Nutrition, Tsukuba International Junior College Manabe 6-7-10, Tsuchiura 300-0051, Ibaraki, Japan

E-mail: nchiba@bronze.ocn.ne.jp

Received: April 8, 2008

Accepted for publication: August 29, 2008 style modifications on CVD risk factors ${ }^{5-8)}$, and these are recommended in the guidelines ${ }^{9,10)}$.

Dietary records and $24 \mathrm{hr}$ dietary recall are dietary survey methods often used to compare dietary habits between populations or among individuals within a population, but a single record or recall is not enough to obtain reliable data on an individual's dietary habits and several records or recalls are needed ${ }^{11)}$. Self-administered diet history questionnaires (DHQ), or food frequency questionnaires have been developed and are often used in epidemiology studyies or health education in Japan ${ }^{12,13)}$. Using these questionnaires, a single examination provides the average intake of nutrients and food groups of a individual within a certain period; however, parficipants might misunderstand the food being surveyed in each question. Category choices for 
frequency and portion size are limited, and this may lead to a difficulty in assessing food intake. There is a possibility that subjects cannot adequately report their frequency or portion size by predetermined choices; i.e., the participant consumes the food far more often, with a far bigger size than the given choices. This information about excessive intake is important in dietary intervention and should not be missed.

We developed an interviewing food frequency and quantity method (FF quantity method) using food models of portion sizes to assess the habitual dietary intake of individuals. Interviewers ask about the frequency and portion sizes of listed common foods using food models, avoiding misunderstanding about the foods. Participants can answer with no restriction on the given choices, allowing for a wide range of frequency and portion size. Interviewers record participants, answers and thus dietary habits might be reflected in the results of the survey more precisely than with a self-administered questionnaire.

The purpose of this study was to evaluate this newly developed FF quantity method using the $24 \mathrm{hr}$ dietary recall method as a reference. We compared the results obtained from the FF quantity method among Japanese men and women with those obtained from the means of four $24 \mathrm{hr}$ dietary recalls performed on the same participants in a highly standardized manner for the INTERMAP Study (International Study of Macro- and Micro-nutrients and Blood Pressure ${ }^{14)}$.

\section{Participants and Methods}

\section{Development of FF Quantity Method}

We developed an interviewing FF quantity method using portion-sized food models. The foods used in this method were selected to cover the major sources of protein $(97 \%)$, carbohydrates $(96 \%)$, fat (96\%), alcohol and $97 \%$ of total energy intake from the results of the National Nutrition Survey of Japan conducted among Japanese general population ${ }^{14,15)}$.

In this method, participants were asked about their average intake of food and beverages during a period of one or two months prior to the interview using the questionnaire, Which consisted of 134 questions (Table 1). For cereals, meat, fish and shellfish, the frequency and portion-size were asked, aided by portion sized food models (closed-ended questions). For vegetables, fruits, sweets and snacks, open-ended questions asking for the names of food items were used, because there are wider varieties of items in these food groups, with seasonal variation, as well as nutrient variation (i.e., fat content, water content), and it may be difficult for participants to answer the ques-
Table 1. Foods included in the Food Frequency and Quantity Method

\begin{tabular}{|c|c|}
\hline Foods & \\
\hline Foods with closed-ended questions & questions \\
\hline \multicolumn{2}{|l|}{ Cereals } \\
\hline Rice & 3 \\
\hline Bread & 5 \\
\hline Noodles & 5 \\
\hline Other cereals & 4 \\
\hline \multicolumn{2}{|l|}{ Fish } \\
\hline Fish & 5 \\
\hline Shellfish & 5 \\
\hline $\begin{array}{l}\text { Fish/shellfish products } \\
\text { (fish cake, canned fish, etc.) }\end{array}$ & 4 \\
\hline \multicolumn{2}{|l|}{ Meat } \\
\hline Meat & 7 \\
\hline Meat products (ham, sausage, etc.) & 3 \\
\hline \multicolumn{2}{|l|}{ Soybean and soybean products } \\
\hline Tofu & 2 \\
\hline Other soybean products & 7 \\
\hline Eggs & 1 \\
\hline Salted vegetables & 3 \\
\hline Potatoes & 1 \\
\hline \multicolumn{2}{|l|}{ Milk and dairy products } \\
\hline Milk & 3 \\
\hline Cream and whitener & 4 \\
\hline Yoghurt and cheese & 4 \\
\hline Ice cream & 4 \\
\hline Fats and oils & 8 \\
\hline Seasonings & 5 \\
\hline Non-alcoholic beverages & 11 \\
\hline (subtotal) & 94 \\
\hline Foods with open-ended questions & answer columns \\
\hline Vegetables & \\
\hline Vegetables for breakfast & 6 \\
\hline Vegetables for lunch & 6 \\
\hline Vegetables for supper & 8 \\
\hline Snacks & 6 \\
\hline Fruit & 6 \\
\hline Nuts & 4 \\
\hline Alcoholic beverages & 4 \\
\hline (subtotal) & 40 \\
\hline Total & 134 \\
\hline
\end{tabular}

tions. Participants reported the names of foods together with their frequency. For foods reported for the openended question, interviewers assigned food codes according to food lists after the interviews to calculate nutrient intake. Examples of dialogues using the ques- 
Table 2. Outlines of questions asked in the Food Frequency and Quantity Method

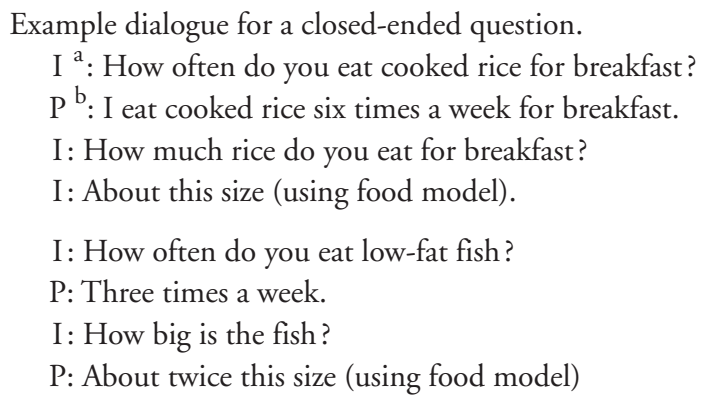

Example dialogue for a closed-ended question.

$I^{a}$ : How often do you eat cooked rice for breakfast?

$\mathrm{P}^{\mathrm{b}}$ : I eat cooked rice six times a week for breakfast.

I: How much rice do you eat for breakfast?

I: About this size (using food model).

I: How often do you eat low-fat fish?

P: Three times a week.

I: How big is the fish?

P: About twice this size (using food model)

Interviewer record frequency and gram amount of the food during the interview.

Example dialogue for a open-ended question.

I: Please tell me which vegetables you often eat for supper.

P: I often eat spinach, carrots, onions, lettuce, and tomatoes.

I: How often do you eat spinach for supper?

P: About four times a week.

I: How much spinach, do you usually eat?

P: About half of this model (using the food model).

I: How often do you eat lettuce?P: About two times a week.

P: About twice a week.

I: How much lettuce, do you usually eat?

P: About twice this size (using the food model)

Interviewer records the type and gram amount of the vegetable during the interview, and assigns a food code for the vegetable after the interview.

${ }^{\mathrm{a}}$, interviewer; ${ }^{\mathrm{b}}$, participant.

tionnaire are listed in Table 2.

\section{Dietary Survey of the INTERMAP Study}

The INTERMAP Study in Aito Town, a rural area in Shiga prefecture located in central Japan, was carried out from October 1996 to March 1997, and the participants were men and women aged 40-59 years who were randomly selected from the general population $(n=259 \text {; response rate, } 38 \%)^{16)}$. Four indepth $24 \mathrm{hr}$ dietary recalls were performed for each participant by trained interviewers using portion-sized food models ${ }^{14,16)}$. Interviewers asked about each individual's type and amount of food and beverages during the 24 hours prior to the interview, using procedures in accordance with INTERMAP national and international quality control stipulations ${ }^{16)}$. Each interview took 30 to 50 minutes. Nutrient intake was calculated using the INTERMAP food table; an integrated food table updated from the Standard Tables of Food Composition in Japan (4th edition) ${ }^{17,18)}$. Means of nutrient intake and food group intake of four $24 \mathrm{hr}$ recalls were calculated for each participant and used in analyses.

\section{FF Quantity Method Survey}

We invited 90 individuals who were randomly selected from the 259 INTEMRAP participants for the FF quantity survey, and 76 individuals enrolled (37 men and 39 women, response rate: 84\%) in April 1998, 12 to 18 months after the original INTERMAP survey. The survey was carried out by four trained interviewers who performed $24 \mathrm{hr}$ dietary recalls in the INTERMAP survey. Nutrient intake was calculated using the INTERMAP food table ${ }^{18)}$.

\section{Data Analysis}

Foods reported in the surveys were classified into 12 food groups. We compared nutrient intake, food intake by food groups in crude values $(\mathrm{g})$, percentage energy intake ( $\% \mathrm{kcal})$, and caloric density $(\mathrm{g} / 1000$ $\mathrm{kcal}$ or $\mathrm{mg} / 1000 \mathrm{kcal}$ ) by the two methods. Atwater's caloric conversion factors were used to calculate percentage energy intake for macronutrient intakes: 4 $\mathrm{kcal} / \mathrm{g}$ for protein, $9 \mathrm{kcal} / \mathrm{g}$ for fat, and $4 \mathrm{kcal} / \mathrm{g}$ for carbohydrates. The paired $t$-test was used to compare values. Differences in nutrient intake between two methods were calculated by the percentages of different values by the two methods divided by those by $24 \mathrm{hr}$ recalls.

For each nutrient and food intak, quintiles were created and percentages of agreement within the same or adjacent quintile of those intakes, both in crude values and energy adjusted values, were examined. Spearman's correlation coefficients were used to assess the relationship between dietary intakes of individuals determined by the two methods with and without energy adjustment. Z-score was used to test the difference in the correlation coefficients before and after energy adjustment.

The significance level was set at 0.05 . Systat (Systat Corp., USA) software was used for statistical analyses.

\section{Results}

Table 3 shows nutrient intakes determined by $24 \mathrm{hr}$ dietary recall and by the FF quantity method. Total energy intake and nutrient intake in crude values by our method were on average lower than those by $24 \mathrm{hr}$ recalls; differences $(\%)$ were $-6.5 \%$ for protein $(p=0.625),-13.9 \%$ for fat $(p=0.005)$, and $-7.1 \%$ for carbohydrate $(p=0.008)$. When converted into percentage energy intake, the differences were lower; $1.4 \%$ for protein $(p=0.625),-7.0 \%$ for fat $(p=0.003)$, and $0.9 \%$ for carbohydrate $(p=0.431)$. 
Table 3. Nutrient intake in crude values, percentage energy intake, and caloric density, determined by $24 \mathrm{hr}$ dietary recall method and by food frequency and quantity method (our method). Mean (SD), 76 men and women aged 40-59, Aito, Shiga, Japan, 1997-1998. Differences are calculated by percentages of different values by two methods divided by those by $24 \mathrm{hr}$ recall

\begin{tabular}{|c|c|c|c|c|}
\hline & 24-hour recall & Our method & \multirow{2}{*}{ Difference (\%) } & \multirow{2}{*}{$p$ value } \\
\hline & $n=76$ & $n=76$ & & \\
\hline \multicolumn{5}{|l|}{ Crude values } \\
\hline Energy intake (kcal) & $2283(556)$ & $2095(626)$ & -8.2 & $<0.001$ \\
\hline Protein (g/day) & $84.5(23.6)$ & $79.0(30.0)$ & -6.5 & 0.625 \\
\hline Total fat (g/day) & $58.1(18.4)$ & $50.0(20.9)$ & -13.9 & 0.005 \\
\hline SFA (g/day) & $15.3(5.5)$ & $13.5(6.4)$ & -11.8 & 0.034 \\
\hline PUFA (g/day) & $15.3(4.7)$ & $12.8(4.8)$ & -16.3 & 0.001 \\
\hline Cholesterol (mg/day) & $396(183)$ & $328(165)$ & -17.2 & 0.010 \\
\hline Carbohydrates (g/day) & $323(76)$ & $300(88)$ & -7.1 & 0.008 \\
\hline Sugar (g/day) & $16.1(8.0)$ & $21.0(23.8)$ & 30.4 & 0.066 \\
\hline Alcohol (g/day) & $12.1(22.7)$ & $12.8(19.3)$ & 5.8 & 0.668 \\
\hline Salt (g/day) & $12.8(3.5)$ & $12.3(6.4)$ & -4.0 & 0.522 \\
\hline Potassium (mg/day) & 3005 (836) & $2598(1041)$ & -13.5 & 0.005 \\
\hline \multicolumn{5}{|l|}{ Percentage energy intakes } \\
\hline Protein (\% kcal) & $14.8(2.3)$ & $15.0(2.9)$ & 1.4 & 0.625 \\
\hline Total fat $(\% \mathrm{kcal})$ & $23.0(4.6)$ & $21.4(5.0)$ & -7.0 & 0.003 \\
\hline SFA (\% kcal) & $6.1(1.5)$ & $5.7(1.6)$ & -5.9 & 0.049 \\
\hline PUFA (\% kcal) & $6.1(1.3)$ & $5.6(1.3)$ & -7.4 & 0.003 \\
\hline Cholesterol (mg/1000 kcal) & $173(62)$ & $155(53)$ & -10.4 & 0.021 \\
\hline Carbohydrates (\% kcal) & $57.2(6.9)$ & $57.7(6.5)$ & 0.9 & 0.431 \\
\hline Sugar (\% kcal) & $7.3(3.9)$ & $9.6(7.8)$ & 31.5 & 0.009 \\
\hline \multicolumn{5}{|l|}{ Caloric density } \\
\hline Alcohol (g/1000 kcal) & $4.6(8.2)$ & $5.6(8.4)$ & 21.7 & 0.050 \\
\hline Salt (g/1000 kcal) & $6.2(1.3)$ & $5.8(1.9)$ & -5.7 & 0.641 \\
\hline Potassium (mg/1000 kcal) & $1336(299)$ & $1254(383)$ & -6.1 & 0.041 \\
\hline
\end{tabular}

SFA, saturated fatty acids; PUFA, polyunsaturated fatty acids

$P$ values are significant by paired $t$-test.

Intake of SFA, PUFA, cholesterol, and potassium estimated by our method was significantly lower than by $24 \mathrm{hr}$ recall both in crude and adjusted values. There was no significant difference in salt intake estimated by the two methods both in crude value and caloric density.

Table 4 shows intake by food groups by $24 \mathrm{hr}$ recall and our method in crude values $(\mathrm{g})$ and caloric density $(\mathrm{g} / 1000 \mathrm{kcal})$. For intake of cereals, fish and shellfish, dairy products (other than milk and yogurt), vegetables, and fruits, our method gave values similar to those determined by $24 \mathrm{hr}$ recall in crude values. Intake of meat tended to be lower with our method (difference not significant). Intake of eggs, potatoes, sweets and snacks, and fats and oils determined by our method was significantly lower than those determined by $24 \mathrm{hr}$ recall. We found significantly greater intake of milk, yogurt, and sugar with our method. Although the differences in the intake of eggs, potatoes, sweets and snacks, and fats and oils was reduced in caloric density, it was still significantly different. Intake of soybeans and soybean products, and cereals became significantly greater with our method than with $24 \mathrm{hr}$ recall in caloric density.

Table 5 shows the gender-specific comparison of intake of energy (kcal), major nutrients (\% kcal), and major food groups $(\mathrm{g} / 1000 \mathrm{kcal})$ determined by the two methods. In men, energy intake, percentage energy intake from protein, total fat, SFA, and PUFA, fish and shellfish, and meat determined by our method were significantly lower than by $24 \mathrm{hr}$ recall. In women, intake of all nutrients and food groups mentioned above was similar.

Table 6 shows the percentage of agreement 
Table 4. Intake by food group determined by $24 \mathrm{hr}$ dietary recall and by food frequency and quantity method (our method), in crude values and caloric density. Means (SD), 76 men and women aged 40-59, Aito, Shiga, Japan, 1997-1998. Differences are calculated by percentages of differences of the two methods divided by values by $24 \mathrm{hr}$ recall

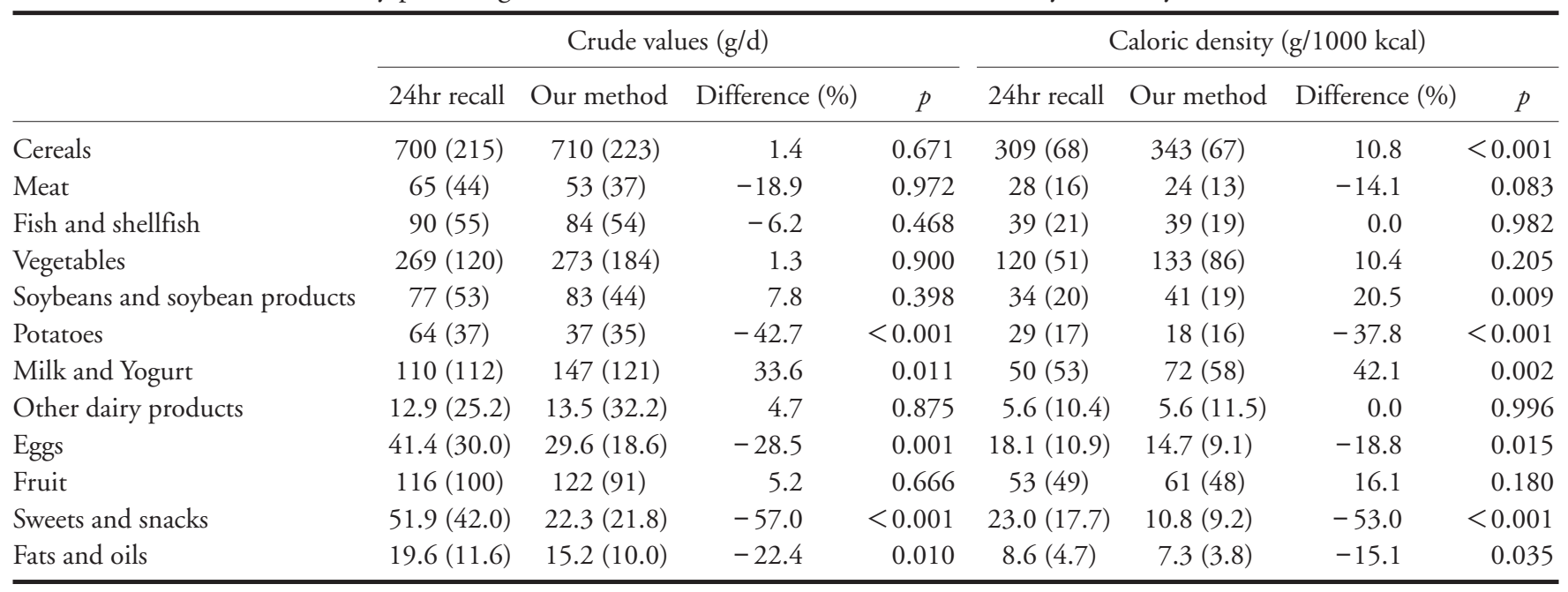

Table 5. Sex-specific intake of energy, major nutrients (\% kcal), and major food groups (g/1000 kcal) determined by $24 \mathrm{hr}$ dietary recall and food frequency quantity method (our method) among 37 men and 39 women aged 40-59. Mean (SD), Aito, Shiga, Japan, 1997-1998

\begin{tabular}{|c|c|c|c|c|}
\hline & $24 \mathrm{hr}$ recall & Our Method & Difference $(\%)$ & $p$ \\
\hline Men & \multicolumn{2}{|c|}{$n=37$} & & \\
\hline Age (years) & \multicolumn{2}{|c|}{$49.7(6.0)$} & & \\
\hline Total energy (kcal) & $2523(632)$ & $2240(417)$ & -11.2 & 0.007 \\
\hline Protein (\% kcal) & $14.5(2.1)$ & $14.1(2.6)$ & -2.8 & 0.008 \\
\hline Total fat (\% kcal) & $21.5(4.6)$ & $18.9(4.5)$ & -12.1 & 0.001 \\
\hline SFA (\% kcal) & $5.5(1.4)$ & $5.0(1.5)$ & -9.1 & 0.010 \\
\hline PUFA (\% kcal) & $5.7(1.4)$ & $5.0(1.1)$ & -12.3 & 0.001 \\
\hline Carbohydrates (\% kcal) & $55.3(7.9)$ & $57.2(7.3)$ & 3.4 & 0.055 \\
\hline Fish and shellfish (g/1000 kcal) & $42.6(22)$ & $36.0(16)$ & -15.5 & 0.013 \\
\hline Meat $(\mathrm{g} / 1000 \mathrm{kcal})$ & $27.1(16)$ & $23.9(16)$ & -11.8 & 0.359 \\
\hline Women & \multicolumn{2}{|c|}{$n=39$} & & \\
\hline Age (years) & \multicolumn{2}{|c|}{$49.6(6.1)$} & & \\
\hline Total energy (kcal) & $2054(351.0)$ & $1958(754.0)$ & -4.7 & 0.356 \\
\hline Protein (\% kcal) & $15.2(2.5)$ & $15.9(2.9)$ & 4.6 & 0.120 \\
\hline Total fat (\% kcal) & $24.4(4.3)$ & $23.7(4.4)$ & -2.9 & 0.299 \\
\hline SFA (\% kcal) & $6.6(1.5)$ & $6.4(1.4)$ & -3.0 & 0.409 \\
\hline PUFA (\% kcal) & $6.3(1.3)$ & $6.1(1.2)$ & -3.2 & 0.315 \\
\hline Carbohydrates (\% kcal) & $58.9(5.3)$ & $58.1(5.8)$ & -1.4 & 0.400 \\
\hline Fish and shellfish (g/1000 kcal) & $42.6(21)$ & $42.6(20)$ & 0.0 & 0.095 \\
\hline Meat (g/1000 kcal) & $27.1(16)$ & $24.7(10)$ & -8.9 & 0.086 \\
\hline
\end{tabular}

$P$ values are significant by paired $t$-test.

within quintile intake of total energy, nutrient and food groups with and without energy adjustment by the two methods. For nutrient intake, percentage agreement within adjacent categories by the two methods ranged from 55\% (potassium) to 86\% (alcohol) in crude values. In energy-adjusted values, percentage agreements increased for most nutrients while those for PUFA, sugar, and alcohol remained 
Table 6. Percentage of agreement within quintile intake of nutrients and food groups without (crude) and with energy adjustment (adjusted) between $24 \mathrm{hr}$ dietary recall method and our method in 37 men and 39 women (aged 40-59), Aito, Shiga, Japan, 1997-1998

\begin{tabular}{|c|c|c|c|c|c|c|}
\hline & \multicolumn{3}{|c|}{ Crude } & \multicolumn{3}{|c|}{ Adjusted $^{\dagger}$} \\
\hline & Same quintile & Adjacent quintile $^{\S}$ & Opposite quintileq & Same quintile & Adjacent quintile & Opposite quintile \\
\hline Energy & $28 \%$ & $63 \%$ & $3 \%$ & - & - & - \\
\hline Protein & $18 \%$ & $59 \%$ & $3 \%$ & $34 \%$ & $71 \%$ & $1 \%$ \\
\hline Total fat & $26 \%$ & $62 \%$ & $4 \%$ & $34 \%$ & $78 \%$ & $4 \%$ \\
\hline SFA & $32 \%$ & $74 \%$ & $4 \%$ & $38 \%$ & $80 \%$ & $3 \%$ \\
\hline PUFA & $21 \%$ & $63 \%$ & $4 \%$ & $25 \%$ & $63 \%$ & $0 \%$ \\
\hline Cholesterol & $24 \%$ & $72 \%$ & $3 \%$ & $30 \%$ & $68 \%$ & $4 \%$ \\
\hline Carbohydrate & $28 \%$ & $67 \%$ & $0 \%$ & $30 \%$ & $72 \%$ & $3 \%$ \\
\hline Sugar & $28 \%$ & $64 \%$ & $3 \%$ & $32 \%$ & $66 \%$ & $4 \%$ \\
\hline Alcohol & $70 \%$ & $86 \%$ & $0 \%$ & $70 \%$ & $86 \%$ & $0 \%$ \\
\hline Salt & $26 \%$ & $62 \%$ & $3 \%$ & $22 \%$ & $58 \%$ & $4 \%$ \\
\hline Potassium & $24 \%$ & $55 \%$ & $5 \%$ & $37 \%$ & $72 \%$ & $1 \%$ \\
\hline Cereals & $51 \%$ & $83 \%$ & $0 \%$ & $46 \%$ & $76 \%$ & $1 \%$ \\
\hline Meat & $21 \%$ & $67 \%$ & $5 \%$ & $22 \%$ & $59 \%$ & $4 \%$ \\
\hline Fish and shellfish & $28 \%$ & $64 \%$ & $1 \%$ & $24 \%$ & $66 \%$ & $1 \%$ \\
\hline Eggs & $30 \%$ & $72 \%$ & $4 \%$ & $26 \%$ & $67 \%$ & $5 \%$ \\
\hline Soybean and soybean products & $25 \%$ & $62 \%$ & $4 \%$ & $21 \%$ & $57 \%$ & $3 \%$ \\
\hline Milk and yogurt & $30 \%$ & $74 \%$ & $0 \%$ & $36 \%$ & $76 \%$ & $0 \%$ \\
\hline Other dairy products & $34 \%$ & $67 \%$ & $5 \%$ & $32 \%$ & $70 \%$ & $5 \%$ \\
\hline Vegetables & $26 \%$ & $64 \%$ & $5 \%$ & $34 \%$ & $64 \%$ & $5 \%$ \\
\hline Potatoes & $25 \%$ & $57 \%$ & $7 \%$ & $24 \%$ & $59 \%$ & $5 \%$ \\
\hline Fruit & $21 \%$ & $57 \%$ & $4 \%$ & $26 \%$ & $62 \%$ & $4 \%$ \\
\hline Sweets and snacks & $28 \%$ & $64 \%$ & $3 \%$ & $32 \%$ & $66 \%$ & $4 \%$ \\
\hline Fats and oils & $16 \%$ & $57 \%$ & $7 \%$ & $16 \%$ & $57 \%$ & $7 \%$ \\
\hline
\end{tabular}

SFA: saturated fatty acids, PUFA: polyunsaturated fatty acids.

${ }^{\dagger}$ : Adjusted values are the percentage energy intake of protein, carbohydrate, fat, SFA, PUFA, and for food groups, cholesterol, salt and potassium, divided by total energy intake.

: The two methods categorized intake into the same quintile.

§: The two methods categorized intake into the same and adjacent quintiles (one method categorized intake into the first quintile, while the other method categorized it into the first and second quintile; one method categorized intake into the second quitile while the other method categorized it into the first, second or third quintiles, and so on).

ๆ: The two methods categorized nutrient intake into opposite quintiles (one method nutrient categorized intake into the first quintile while the other method categorized it into the fifth quintile and vice versa).

unchanged. For food groups, percentage agreement ranged from $57 \%$ (potatoes, fruits, and fats and oils) to $83 \%$ (cereals) in crude values. Percentage agreement in food group intake did not change essentially after energy adjustment. The percentages of participants categorized into opposite quintiles were less than 5\% for nutrient intakes and less than $7 \%$ for food group intake.

Table 7 shows correlation coefficients between the intake of nutrients and food groups determined by $24 \mathrm{hr}$ dietary recall and our method in crude values and energy-adjusted values. Correlation coefficients between crude values were significant for total energy intake and all nutrients other than potassium $(p=0.067)$. Correlation coefficients for nutrients other than potassium ranged from $r=0.120(p=0.300)$ for vegetables to $r=0.682(p<0.001)$ for cereals $(p<$ $0.001)$. With energy adjustment, most correlation coefficients became higher. Correlation coefficients for the intake of protein, total fat, SFA, and PUFA significantly increased with energy adjustment $(p<0.05)$.

When evaluated by food groups, the intake of cereals, meats, fish and shellfish, eggs, milk and yogurt, other dairy products, fruits, and sweets and snacks was significantly correlated. Correlation coefficients for these food groups ranged from $r=0.291 \quad(p=0.011)$ for salt to $r=0.716(p<0.001)$ for alcohol. Intake of soybeans and soybean products, vegetables, potatoes, 
Table 7. Spearman's correlation coefficients(r) of intake $(n=76)$ of energy, nutrient and food groups between the 24-hour recall method and the food frequency and quantity method in 76 men and women (aged 40-59), Aito, Shiga, Japan, 1997-1998

\begin{tabular}{|c|c|c|c|c|}
\hline & \multicolumn{2}{|c|}{ Crude } & \multicolumn{2}{|c|}{ Adjusted $^{\dagger}$} \\
\hline & $r$ & $p$ & $r$ & $p$ \\
\hline Energy & 0.394 & $<0.001$ & - & - \\
\hline Protein & 0.327 & 0.004 & 0.477 & $<0.001^{*}$ \\
\hline Fat & 0.334 & 0.003 & 0.564 & $<0.001^{*}$ \\
\hline SFA & 0.419 & $<0.001$ & 0.571 & $<0.001^{*}$ \\
\hline PUFA & 0.230 & 0.046 & 0.417 & $<0.001^{*}$ \\
\hline Cholesterol & 0.458 & $<0.001$ & 0.363 & 0.001 \\
\hline Carbohydrate & 0.532 & $<0.001$ & 0.552 & $<0.001$ \\
\hline Sugar & 0.329 & 0.004 & 0.318 & 0.009 \\
\hline Alcoholic & 0.716 & $<0.001$ & 0.721 & $<0.001$ \\
\hline Salt & 0.291 & 0.011 & 0.228 & 0.048 \\
\hline Potassium & 0.211 & 0.067 & 0.456 & $<0.001^{*}$ \\
\hline Cereals & 0.682 & $<0.001$ & 0.548 & $<0.001$ \\
\hline Meat & 0.261 & 0.023 & 0.245 & 0.033 \\
\hline Fish and shellfish & 0.333 & 0.003 & 0.372 & 0.001 \\
\hline Eggs & 0.425 & $<0.001$ & 0.286 & 0.012 \\
\hline Soybean and soybean products & 0.197 & 0.089 & 0.229 & 0.047 \\
\hline Milk and yogurt & 0.612 & $<0.001$ & 0.632 & $<0.001$ \\
\hline Other dairy products & 0.334 & 0.003 & 0.329 & 0.004 \\
\hline Vegetables & 0.120 & 0.300 & 0.222 & 0.054 \\
\hline Potatoes & 0.148 & 0.201 & 0.208 & 0.071 \\
\hline Fruit & 0.376 & 0.001 & 0.397 & 0.009 \\
\hline Sweets and snacks & 0.376 & 0.001 & 0.397 & $<0.001$ \\
\hline Fats and oils & 0.153 & 0.186 & 0.230 & 0.046 \\
\hline
\end{tabular}

*: Correlation coefficient was significantly increased with adjustment $(p<0.05)$

${ }^{\dagger}$ : Adjusted values were the percentage of energy intake of protein, carbohydrate, fat, SFA, PUFA, and for food groups, cholesterol, salt and potassium, divided by total energy intake.

and fats and oils was not significantly correlated. After energy adjustment, correlation coefficients became significant for the intake of soybeans and soybean products, and fats and oils, but were still not significant for potatoes $(p=0.071)$ and vegetables $(p=0.054)$.

The FF quantity method survey was shared by four interviewers, and each interviewer performed 9 to 18 interviews. There were no significant differences in the averages of interview time, total energy intake, and macro-nutrient intake among interviewers (data not shown).

\section{Discussion}

The results of the newly developed FF quantity method and the mean of four $24 \mathrm{hr}$ recalls for the INTERMAP Study in Aitotown, Japan, performed on the same participants were examined. Nutrient and food group intake relevant to CVD risk factors were compared from various aspects.

For cereals and alcohol, the mean crude intake using the FF quantity method was very similar to that from $24 \mathrm{hr}$ recall $(700 \mathrm{~g}$ vs. $710 \mathrm{~g}$ and $12.1 \mathrm{~g}$ vs. $12.8 \mathrm{~g}$ for cereals and alcohol, respectively) and also showed high correlation coefficients $(0.682$ and 0.716 for cereals and alcohol, respectively). This is an important feature of the FF quantity method because they are both important energy sources and characterize an individual's dietary habits.

As major sources of protein, there were no significant differences in the mean crude intake of fish and shellfish, meat, dairy products other than milk and yogurt, and soybean and soybean products between the two methods, and correlation coefficients between intake from the two methods were significant for both crude and energy-adjusted values, except for soybean and soybean products for which the correlation coefficient became significant after adjustment. The FF 
quantity method gave a significantly lower mean intake than $24 \mathrm{hr}$ recall for eggs and a significantly higher mean intake for milk and yogurt, and both difference remained significant after energy adjustment, but correlation coefficients between the two methods were significant for both food groups and in both crude and adjusted values. These resulted in similar crude protein intake from the two methods and the FF quantity method was thought to be appropriate to estimate an individual's protein source pattern.

As potassium and dietary fiber sources, crude mean vegetable intake obtained from the FF quantity method was very similar to that from $24 \mathrm{hr}$ recall (269 g and $273 \mathrm{~g}$ from FF quantity method and $24 \mathrm{hr}$ recall, respectively), but mean potato intake was significantly lower in both crude and adjusted values. Correlation coefficients were not significant for both food groups in both crude and adjusted values. For fruit, the FF quantity method gave a higher mean intake in both crude and energy-adjusted values but significant correlation coefficients in both crude and adjusted values were shown. Some of the participants participated in INTERMAP data collection in winter and the FF quantity method in spring about 18 months later. The study region is located in a rural area and most of the participants grew theirown vegetable. Seasonal variation due to regional characteristics might have affected the low correlations in these foods. Further evaluation of the FF quantity method might be necessary with regard to the estimation of vegetables and potato intake.

The mean fat and oil intake obtained from the FF quantity method was significantly lower in both crude and energy-adjusted values. The correlation coefficient became significant after energy adjustment, but was not considerable $(r=0.230)$. For discretionary fat and oil intake (dressings and spreads), the frequency and portion sizes were investigated. For non-discretionary intake, the frequency of pan-fried and deepfried from was investigated but portion sizes were not and the prescribed amount was used to calculate total intake. Consideration of the portion sizes of these foods using $24 \mathrm{hr}$ recall or interactive estimation of the portion size of non-discretionary oil using the subject's intake of meat, fish and vegetables obtained from his/ her own FF quantity questionnaire might be helpful to improve the estimate of fats and oils.

Questions were posed to specify the type of oils and fats used; i.e. mixed salad oil, safflower oil, butter, margarine, etc, which resulted in higher correlation coefficients for SFA and PUFA adjusted for total energy intake; $0.571(p<0.001)$ for SFA, and 0.417 $(p<0.001)$ for PUFA. This may also be a favorable aspect of our method in dietary intervention ${ }^{19)}$. For sweets and snacks, mean intake by the FF quantity method was significantly lower in both crude and adjusted values but the correlation coefficients were significant.

As for the estimation of sodium intake, a significant relationship between estimated dietary intake and urinary sodium excretion obtained by two timed 24hour urine collections was observed in the INTERMAP Study ${ }^{20)}$, and the values from the INTERMAP Study were thought to be eligible as reference data. In this study, we also found a significant correlation between estimated intake by the two dietary surveys. This also suggests that the FF quantity method could be used to assess sodium intake; an important feature in a blood pressure control program.

These results gave in high percentage agreement within adjacent quintiles of nutrients and food group intake by the two methods; 55 to $86 \%$ in crude values and 57 to $80 \%$ in energy-adjusted values. This may suggest that the FF quantity method is useful to reveal the dietary pattern of the individual relevant to CVD risk factors within the population, and also to detect the change before and after dietary intervention.

Crude intake values of energy, fat and carbohydrates determined by the FF quantity method were significantly lower than those determined by 24-hour dietary recall; however, energy-adjusted differences (\% differences between \% energy intakes by the two methods) were reduced for all major nutrients (protein, fat, SFA, PUFA, and carbohydrates), in agreement with previous reports ${ }^{11,21)}$. Energy adjustment also improved the correlations of intake of macronutrients, SFA, PUFA, and potassium. Using of the FF quantity method, energy adjusted values may give a more representative pattern of the nutrient intake of participants.

In women, no significant differences were found between total energy intake and percent energy intake of major nutrients, and food group intake, where as significant differences were observed for men (Table 5). The reason for this is not clear. Several validation studies in western countries have examined the gender effect on the difference between results of food-frequency questionnaires and a reference method (weighed food records, or $24 \mathrm{hr}$ recall), and no consistent differences between genders were observed ${ }^{22-24)}$. The Japanese diet has a wider variation of food items as well as cooking procedures than the western $\operatorname{diet}^{16,18)}$, and this might have affected the results of our study. Namely, men may have been less conscious of their diet than women, making it difficult to recall specific food items and to estimate their amounts, as well as frequency, in the Japanese diet. More case showd be 
taken with our FF quantity method and when using the results of the survey for male participants.

In this study, we re-interviewed individuals 12 to 18 months after their INTERMAP participation. Since the INTERMAP Study imposed a considerable burden on participants; four clinic visits with four 24hour dietary recalls, two 24-hour urine collections, multiple BP measurements, and dietary advice at the end of the survey, participants may have modified their dietary habits substantially. The long interval between the two surveys itself may also have affected their lifestyles. There may have been seasonal variation in food intake since the INTERMAP survey was conducted through winter to spring, while dietary interviews using our method were conducted in spring. These factors may have affected dietary habits among participants and may have reduced the relationship between the results obtained by the two methods.

There were no significant differences in the average interview time and nutrient intake among interviewers (data not shown), Showing no major concern. Further study with repeated interviews should be performed for reproducibility.

Japan has experienced a westernization of dietary habits and the nutrient intake pattern has changed, resulting in a change in CVD risk factors, including serum lipid profiles ${ }^{19,25-28)}$. Requests are increasing for a dietary assessment method that enables medical workers to practice effective dietary intervention, and the development of a sophisticated method to estimate long-term usual intake is needed. Our method would therefore be feasible.

\section{Conclusions}

The FF quantity method is suitable to detect differences in nutrient and food group intake important to control of CVD risk factors among Japanese individuals. This method is applicable for dietary surveys and lifestyle modification programs for the prevention of CVD.

\section{Acknowledgements}

The authors are grateful to Professor Stamler, a principal investigator of the INTERMAP Study, for his helpful suggestions. This study was partially supported by a Grant-in-Aid for Scientific Research [A] 09357003, [B] 14370145 from the Ministry of Education, Science, Sports, and Culture, Japan and by Grant 2-RO1-HL50490 from the US National Heart, Lung and Blood Institute, National Institute of Health, Bethesda, Maryland.

\section{References}

1) Ferdinand KC, Kleinpeter MA: Management of hypertension and dyslipidemia. Curr Hypertens Rep, 2006; 8:489496

2) Stamler J, Rose G, Stamler R, Elliott P, Dyer A, Marmot M: INTERSALT study findings. Public health and medical care implications. Hypertension, 1989; 14:570-577

3) Okuda N, Ueshima H, Okayama A, Saitoh S, Nakagawa H, Rodriguez BL, Sakata K, Choudhury SR, Curb JD, Stamler J; INTERLIPID Research Group: Relation of long chain n-3 polyunsaturated fatty acid intake to serum high density lipoprotein cholesterol among Japanese men in Japan and Japanese-American men in Hawaii: the INTERLIPID study. Atherosclerosis, 2005; 178:371-379

4) Harris WS: Fish oils and plasma lipid and lipoprotein metabolism in humans: a critical review. J Lipid Res, 1989; 30:785-807

5) Sacks FM, Svetkey LP, Vollmer WM, Appel LJ, Bray GA, Harsha D, Obarzanek E, Conlin PR, Miller ER 3rd, Simons-Morton DG, Karanja N, Lin PH; DASH-Sodium Collaborative Research Group: Effects on blood pressure of reduced dietary sodium and the Dietary Approaches to Stop Hypertension (DASH) diet. DASH-Sodium Collaborative Research Group. N Engl J Med, 2001; 344:3-10

6) Ueshima H, Mikawa K, Baba S, Sasaki S, Ozawa H, Tsushima M, Kawaguchi A, Omae T, Katayama Y, Kayamori Y, et al: Effect of reduced alcohol consumption on blood pressure in untreated hypertensive men. Hypertension, $1993 ; 21: 248-252$

7) Mori TA, Vandongen R, Beilin LJ, Burke V, Morris J, Ritchie J: Effects of varying dietary fat, fish, and fish oils on blood lipids in a randomized controlled trial in men at risk of heart disease. Am J Clin Nutr, 1994; 59:1060-1068

8) Al-Mahmood AK, Ismail AA, Rashid FA, Azwany YN, Singh R, Gill G: Effect of therapeutic lifestyle changes on insulin sensitivity of non-obese hyperlipidemic subjects: preliminary report. J Atheroscler Thromb, 2007; 14:122127

9) Teramoto T, Sasaki J, Ueshima H, Egusa G, Kinoshita M, Shimamoto K, Daida H, Biro S, Hirobe K, Funahashi T, Yokote K, Yokode M: Executive summary of Japan Atherosclerosis Society (JAS) guideline for diagnosis and prevention of atherosclerotic cardiovascular diseases for Japanese. J Atheroscler Thromb, 2007; 14:45-50

10) Saruta T: The Japanese Society of Hypertension Guidelines for the Management of Hypertension (JSH 2004). Nippon Rinsho, 2005; 63:952-958

11) Willet WC: Nutritional Epidemiology. Oxford University Press, Oxford, 1989

12) Sasaki S, Yanagibori R, Amano K: Self-administered diet history questionnaire developed for health educatin: a relative validation of the test-version by comparison with 3-day diet record in women. J Epidemiol, 1998; 8:203215

13) Sasaki S, Ishikawa T, Yanagibori R, Amano K: Responsiveness to a self-administered diet history questionnaire in a work-site dietary intervention trial for mildly hypercholesterolemic Japanese subjects: correlation between change in dietary habits and serum cholesterol levels. J Cardiol, 
1999; 33:327-338

14) Stamler J, Elliott P, Dennis B, Dyer AR, Kesteloot H, Liu K, Ueshima H, Zhou BF; INTERMAP Research Group: INTERMAP: background, aims, design, methods, and descriptive statistics (nondietary). J Hum Hypertens, 2003; 17:591-608

15) Ministry of Health, Labour and Welfare, Japan: The National Nutrition Survey in Japan, 2000 (in Japanese). Daiichi Shuppan, Tokyo, 2002

16) Dennis B, Stamler J, Buzzard M, Conway R, Elliott P, Moag-Stahlberg A, Okayama A, Okuda N, Robertson C, Robinson F, Schakel S, Stevens M, Van Heel N, Zhao L, Zhou BF; INTERMAP Research Group: INTERMAP: the dietary data--process and quality control. J Hum Hypertens, 2003; 17:609-622

17) The Reources Council, Science and Technology Agency of Japan: The standard tables of food composition in Japan (4th revised ed.) (in Japanese). Printing Bureau, Ministry of Finance, Tokyo, 1982

18) Schakel SF, Dennis BH, Wold C, Conway R, Zhao L, Okuda N, Okayama A, Moag-Stahlberg A, Robertson C, Van Heel N, Buzzard IM, and Stamler J: Enhancing data on nutrient composition of foods eaten by participants in the INTERMAP study in China, Japan, the United Kingdom, and the United States. J Food Comp Anal, 2003; 16:395-408

19) Nosaka N, Maki H, Suzuki Y, Haruna H, Ohara A, Kasai M, Tsuji H, Aoyama T, Okazaki M, Igarashi O, Kondo K: Effects of margarine containing medium-chain triacylglycerols on body fat reduction in humans. J Atheroscler Thromb, 2003; 10:290-298

20) Liu K, Cooper R, McKeever J, McKeever P, Byington R, Soltero I, Stamler R, Gosch F, Stevens E, Stamler J:
Assessment of the association between habitual salt intake and high blood pressure: methodological problems. Am J Epidemiol, 1979; 110:219-226

21) Thompson FE, Byers T: Dietary assessment resource manual. J Nutr, 1994; 124:2245S-2317S

22) Pijls LT, de Vries H, Donker AJ, van Eijk JT: Reproducibility and biomarker-based validity and responsiveness of a food frequency questionnaire to estimate protein intake. Am J Epidemiol, 1999; 150:987-995

23) Marks GC, Hughes MC, van der Pols JC: The effect of personal characteristics on the validity of nutrient intake estimates using a food-frequency questionnaire. Public Health Nutr, 2006; 9:394-402

24) Marks GC, Hughes MC, van der Pols JC: Relative validity of food intake estimates using a food frequency questionnaire is associated with sex, age, and other personal characteristics. J Nutr, 2006; 136:459-465

25) Egusa G, Yamane K: Lifestyle, serum lipids and coronary artery disease: comparison of Japan with the United States. J Atheroscler Thromb, 2004; 11:304-312

26) Egusa G, Watanabe H, Ohshita K, Fujikawa R, Yamane $\mathrm{K}$, Okubo M, Kohno N: Influence of the extent of westernization of lifestyle on the progression of preclinical atherosclerosis in Japanese subjects. J Atheroscler Thromb, 2002; 9:299-304

27) Hata Y, Nakajima K: Life-style and serum lipids and lipoproteins. J Atheroscler Thromb, 2000; 7:177-197

28) Namekata T, Moore D, Knopp R, Marcovina S, Perrin E, Hughes D, Suzuki K, Mori M, Sempos C, Hatano S, Hayashi C, Hasegawa M: Cholesterol levels among Japanese Americans and other populations: Seattle Nikkei Health Study. J Atheroscler Thromb, 1996; 3:105-113 